\title{
How value co-creation and co-destruction unfolds: a longitudinal perspective on dialogic engagement in health services interactions
}

\author{
Debbie Isobel Keeling $^{1}\left(\mathbb{D} \cdot\right.$ Kathleen Keeling $^{2} \cdot$ Ko de Ruyter $^{3,4} \cdot$ Angus Laing $^{5}$
}

Received: 12 August 2017 / Accepted: 12 June 2020 / Published online: 30 June 2020

(C) The Author(s) 2020

\begin{abstract}
Complex services, such as healthcare, struggle to realize the benefits of value co-creation due to the substantial challenges of managing such services over the long-term. Key to overcoming these challenges to value co-creation is a profound understanding of dialogue (i.e., 'quality of discourse' facilitating shared meaning) during service interactions. Contributing to an emerging literature, we undertake a longitudinal, ethnographic study to assess dialogue between professionals and patients through the lens of dialogic engagement (i.e., iterative mutual learning processes that bring about action through dialogue). We develop and empirically support six dialogic co-creation and co-destruction mechanisms that impact on the resolution of tensions and integration of knowledge resources between service providers and consumers. We reveal the multidimensional and dynamic nature of value created or destroyed through these mechanisms in dialogue over time. Taking healthcare as an exemplar, we offer a research agenda for developing our understanding of DE in complex services.
\end{abstract}

Keywords Dialogic engagement $\cdot$ Dialogue $\cdot$ Healthcare services $\cdot$ Complex services $\cdot$ Value co-creation $\cdot$ Value co-destruction Knowledge resources $\cdot$ Patients $\cdot$ Healthcare professionals

During recent years it has been conclusively shown that consumers and service providers across diverse domains benefit from value co-creation (Vargo et al. 2017). Arguably, value co-creation holds the most potential for complex services, such as delivery of healthcare services. In this domain, policy reforms emphasize the development of consumer-centered care and surveys record patients' first priority to be desiring more active involvement in their encounters with healthcare professionals (HCPs) (Deloitte Insights 2018). The emerging consensus is that value co-creation has promise for muchneeded service delivery efficiencies and better health outcomes, against the backdrop of rapid increase in demand and critical service provider pressures (Best et al. 2019). In theory, value co-creation delivers such outcomes through engaging consumer-HCP interactions that facilitate dialogue and shared understanding. In practice, it has been

Manjit Yadav served as Area Editor for this article.

Electronic supplementary material The online version of this article (https://doi.org/10.1007/s11747-020-00737-z) contains supplementary material, which is available to authorized users.

Debbie Isobel Keeling

d.i.keeling@sussex.ac.uk

Kathleen Keeling

Kathy.keeling@manchester.ac.uk

Ko de Ruyter

ko.de_ruyter@kcl.ac.uk

Angus Laing

a.w.laing@lancaster.ac.uk
1 University of Sussex Business School, University of Sussex, Brighton BN1 9SL, UK

2 Alliance Manchester Business School, University of Manchester, M1 3WE, Manchester M15 6PB, UK

3 King's Business School, King's College London, London WC2B 4BG, UK

4 School of Marketing, UNSW Business School, UNSW Sydney, Kensington 2052, Australia

5 Lancaster University Management School, Lancaster University, Lancaster LA1 4YX, UK 
demonstrated that making consumer-HCP interactions deliberately more balanced leads to empowered care, with consumers collaborating in joint decisions on personalized treatments (Health Foundation 2012).

Nonetheless, at the same time, there is accumulating proof of value co-destruction during service encounters as an unintended consequence (Palumbo 2017). This is attributed to a variety of challenges identified in relation to patient-HCP interactions in health service encounters, such as power imbalances, choice restriction, "reluctant" or unready consumers and perceptions of care as a "negative" service (Malshe and Friend 2018). Hence, positive outcomes can be eclipsed by patients' reluctance to collaborate and/or their withdrawal from the process; a recent study by Joseph-Williams et al. (2017) shows that patient reticence is frequently mistaken by HCPs for unwillingness to engage. Value co-destruction is also attributed to the heterogeneity in service delivery over time (Echeverri and Skålén 2011; Makkonen and Olkkonen 2017). Health services delivery typically involves multiple HCPs, plus consumers' perspectives and abilities change during the process (Joseph-Williams et al. 2017; Palumbo 2017). Given the apparent interplay between these forces, we address the clear need to develop an in-depth understanding of how value co-creation and co-destruction evolve and be traced back to the inputs made during interactions between consumers and service providers over time.

To address this need we turn to recent theorizing on Dialogic Engagement (DE) (Kent and Taylor 2018). DE is a body of scholarship that focuses on understanding how inputs during interactions and the emergent learning can facilitate development of a shared meaning between those involved. For DE theorists, this shared meaning is the foundation for further actions to take place (e.g., shared decision making). While DE is relevant for explicating how value co-creation and co-destruction emerge during service interactions, extant literature has been largely silent on identifying DE as vital in underpinning the value co-creation process.

Our argument for extending the scholarship base on value-based service delivery is built on four key points. First, and fundamentally, we argue that shared meaning is the basis for value co-creation. DE directly points to the "quality" of the dialogue as aiding articulation of knowledge and co-ordination of new shared meaning between actors (Cissna and Anderson 2012). Second, DE identifies conceptual principles that define an "ideal" genuine dialogue within interactions needed to facilitate shared perspectives. Further, DE also recognizes the potential for negative outcomes if dialogue is incorrectly applied, exploited, or mismanaged; paralleling value co-creation theorizing (Vargo et al. 2017). Third, DE positions inevitable tensions in dialogue not as a negative attribute but as a catalyst for the emergence of new shared meaning, such as is envisaged in value co-creation (Mele 2011). That is, dialogue can enable value co-creation through resolving tensions between actors (Grönroos and Voima 2013). Fourth, DE takes a dynamic view. Resolving tensions and developing shared meaning take place incrementally over time and multiple interactions. Implying that value co-creation and/or co-destruction is also dynamic. This translates well to the perspective on complex services. Focusing on how the dynamics of dialogue within service interactions impacts on value co-creation/destruction, we take fundamental DE theory and unpack its potential for services marketing theory and practice. As such, we provide a detailed examination of the role of $\mathrm{DE}$ as a source of value creation or destruction over time for complex services.

We offer the following contributions. First, and substantively, we conceptualize and contextualize three DE principles and theorize on their role in value co-creation and co-destruction within the delivery of complex services. We achieve this by identifying and demonstrating how these conceptual DE principles can be operationalized within service interactions by defining six dialogic mechanisms: three that promote value co-creation and three that promote value co-destruction within observed service interactions. These mechanisms work to address tensions inherent in dialogue by determining how three forms of knowledge (priorities, concerns, and experiences) are integrated or not within service interactions.

Second, we conceptualize and track how value develops longitudinally across multiple interactions. Each mechanism results in specific consumer-relevant values (shared forms of efficiency, excellence and esteem). Importantly, value is dynamic reflecting the longitudinal nature of complex services. As such, at the aggregate level we identify two dominant pathways: one that describes how value is co-created and one that describes how value is co-destroyed over the service delivery process. Articulating these pathways allows a better explanation of the instances within which value may be cocreated or co-destroyed with the prospect of more adaptive service practices.

\section{Integrative conceptual and empirical approach}

To develop our contributions, we use an approach that blends theoretical development of DE with empirical observation of the complex service setting of healthcare. In parallel, we offer a linear narrative of how DE dynamically relates to value creation and destruction over time: 
- In part 1 , we integrate theorizing of $\mathrm{DE}$ and value cocreation/destruction with observed data of dialogue within service interactions to provide a rich conceptualization of the dialogic mechanisms of co-creation and codestruction.

- In part 2, we explore the action of these mechanisms over time, and define and demonstrate the consumerrelevant values emerging through dialogue, taking a dynamic view of value as it unfolds across linked service interactions.

\section{Complex service context}

The research setting is the UK national public health service, where care is free at the point of delivery. The service relies on central government funding raised through taxation (deducted at source), other minor funding sources include consumer charges (e.g., prescription charges). Consumers have limited choices with regard to the service process. Outside of emergency service, diagnosis is through primary care (e.g., General Practitioner, Nurse Practitioner, Dentist, or Optician), followed by referral to secondary care (e.g., consultant-led services around specialist areas). In most circumstances consumers now have the right to choose which hospital or clinic they attend, but available treatments are subject to funding restrictions, and there are regional variations in the delivery and quality of services. Consumers can pay to use a private healthcare service, which provides more choice, but there is limited uptake of such services (mainly through insurance) and large regional differences.

\section{Approach, entrée, and recruitment}

Following Hardyman et al. (2015), our ethnographic study captures the naturalistic context within which health services are delivered. Following full ethics approvals obtained via the pan-NHS ethics framework, recruitment of primary care practices was supported by regional administrative organizations. Telephone negotiations with practice managers were, where requested, followed by face-toface presentations. We also recruited professionals from within secondary care organizations and specialist clinics. Overall, we recruited 13 specialist practitioners (4 female: 9 male; mean age $=49.5$ years, range $37-63$ years) in primary and secondary care practices. With their help, we recruited patients during the diagnosis stage to enable us to observe them along their care pathway $(N=24,9$ female: 15 male; mean age $=59.5$ years, range $35-77$ years; $20 \mathrm{married} / \mathrm{co}$ habiting: 4 separated/divorced/widowed; 10 higher education: 7 further education: 7 high school education; 22 White British; 1 Indian British; 1 Black African; 12 were retired). We included those with multiple conditions as this was the reality for patients and professionals (19 single condition, 5 multiple condition). Thus, all had no prior experience with their focal condition, but some had experience with other conditions.

Entrée was overt; contact with patients was made in the clinical practice and they provided their informed consent. Data were captured through "overt participant" observation (Atkinson and Hammersley 2007). That is, observation conducted with the explicit agreement and knowledge of informants, where the general purpose of the study is not hidden. A researcher (from a team of 3 ) accompanied patients to HCP consultations (clinicians, consultants, specialist nurses and allied professionals). We observed 61 consultations $(15 \mathrm{~h} 51$ mins, mean consultation 15 $16 \mathrm{~min}$, range $=3-35 \mathrm{~min}$ ), audio recorded 55 consultations (transcription total word count: consultations = 153,394). Six were not audio recorded due to HCP refusal. Consultations were then transcribed for data analysis.

\section{Analysis}

Longitudinal analysis aims to understand the mechanisms and conditions that facilitate or hinder change within the context of the dynamic interplay between consumer and service (Saldana 2013). Importantly, Saldana (2013, p.161) identifies that change is not "singular and isolated," and distinguishes complex "influences and affects" observed over time from simple "causes and effects." Longitudinal research aids the identification of influences and affects to reflect the processual and complicated nature of observed change. This necessitates a multi-stage approach: cross-sectional analysis of themes at key time points; repeat cross-sectional analysis to identify changes over time; individual case narratives to gain a holistic understanding of the changes over time; cross-case comparison to identify aggregate level patterns of change (Saldana 2013). Before analysis, we orientated ourselves with familiarizing reads through the consultations, followed by initial comparisons between our data and our conceptual underpinnings, where, rather than coding data, we made an initial sort of our data according to elements identified within the literature.

Part 1: Dialogic engagement mechanisms We set out to identify the dialogic mechanisms that could underpin the cocreation or co-destruction of shared meaning within the observed consultations. To cross-section our data, we organized the consultations by time as early, intermediate and review consultations. We identified and open-coded sections of dialogue to identify dialogic mechanisms and the tensions and resources to which they were related. Our coding was informed, but not limited by, the recognized tensions that we identified in the literature. We first applied this process to the consultations within early consultations, then, allowing a repeat 
cross-sectional analysis, to intermediate then review consultations. This was inevitably an iterative process. We applied axial coding to identify distinct (higher order) mechanisms in dialogue at the aggregate level. Again, we used the cross-sectional and repeat cross-sectional approach. We identified three cocreation and three co-destruction mechanisms linked to specific tensions and resource integration, which we were confident were consistent across the observed service stages.

Part 2: Longitudinal value Exploring the link between value and mechanisms, and the possible evolution of value over time, we returned to the case by case consultations, now annotated with our codings from part 1 . For each case we focused on how mechanisms progressed across linked consultations and their relation to what, we coded as, emergent value. To code value we used, but were not limited to, Holbrook's (1999) typology as a referent point combined with our premise from DE that value from dialogue can be understood in terms of developing shared meaning. Having coded each case accordingly, we moved from this emic perspective of individual cases to a more etic understanding by identifying commonalities across cases in terms of co-creation/destruction mechanisms and value. Enabling us to identify aggregate level patterns of mechanisms and values.

Following Miles and Huberman's (1994) interpretation of triangulation in qualitative research, we include necessary diversity in our data sources: (1) patients with different and multiple conditions; (2) diverse actor perspectives (e.g., patients and HCPs); and (3) various, naturally occurring, healthcare delivery sites. Further, "time triangulation," a particular feature of longitudinal research, was achieved through the multiple, linked time points of observations, which supports our findings of "cumulative change" (Saldana 2013, p. 105). Also, careful recording and transcribing preserved the data authenticity and bounded us to not incorporate interpretations beyond what it contains. These measures are important as in emotive situations such as health, participant observers can become emotionally involved and the need to challenge biases is high. Regular team meetings discussed the immersion and emotional wellbeing of the researchers, and a multiresearcher data collection team further guarded against potential biases and oversimplified interpretations. For this paper, three researchers brought an "outside" perspective having not been involved in data collection.

\section{Part 1: From dialogic engagement principles to dialogic engagement mechanisms}

We argue that DE is an appropriate guiding theoretical framework for studying value co-creation and value codestruction emerging from interactions between consumers and service providers. DE theory posits that through dialogue, people can exchange knowledge and reach mutual recognition and learning (Bebbington et al. 2007), bringing about new shared meaning (Gergen et al. 2002). For DE, tension is integral to interaction. Working through tensions enables shared meaning to be contextualized and grounded (Kent and Taylor 2018). For example, when exploring condition treatment options, the patient and HCP may come to mutually understand each other's perspectives on and hence tensions about treatment(s). For the patient, the side effects of one treatment may be unacceptable (e.g., incontinence), despite understanding that, from the HCP perspective, it is the most efficacious. Shared meaning enables both parties to go on to make a transparent decision about treatment choices. This positive role of resolving tensions within dialogue is the ideal (Bakhtin 1986; Freire 2005), but DE recognizes the challenge of achieving the engagement of both parties and resolving tensions.

DE offers a set of conceptual principles to achieve the "ideal" dialogue. To understand the efficacy of such principles in bringing about shared meaning, it is necessary to explore the realization of the principles within specific dialogic contexts (Bebbington et al. 2007), such as, in this study, health service delivery. Despite some divergence, we argue that three DE principles emerge as a consensus in the literature: dialogic democracy, intellectual honesty, and affirmation (Bebbington et al. 2007; Gergen et al. 2002; Kent and Taylor 2018). From these three fundamental DE principles, we conceptualize and demonstrate how they translate into mechanisms within complex service interactions. The DE principles provide a positive lens through which to understand dialogue in interactions, consistent with co-creation. Expanding this view, we contrast this with the alternative "negative" lens, consistent with co-destruction.

In our case, service interactions are the consultations that take place between patients and HCPs. Gergen et al. (2002) provide some insight on how these principles might be operationalized. They theorize that the principles require conversational properties: (taking) relational responsibility and coordination, affirmation, and (allowing) self-expression and reflexivity. Though not all properties need to be present in every interaction (Kent and Taylor 2018), we argue that the absence or non-enactment of these properties could dampen "active players" and be the basis for negative reactions, potentially, value co-destruction. From the data, we identify six mechanisms operating within the observed consultations, which map onto the three broad DE principles. The (what we label) co-creation mechanisms or codestruction mechanisms work by addressing (or exacerbating) tensions in dialogue (power, legitimacy of perspective, and socio-emotional; Mele 2011). They achieve this by enabling or hindering the integration of knowledge resources 
Table 1 Dialogic mechanisms and shared resources mapped against DE principles

\begin{tabular}{|c|c|c|c|}
\hline DE principle & Co-creation mechanism & Co-destruction mechanism & $\begin{array}{l}\text { Resource } \\
\text { integration }\end{array}$ \\
\hline $\begin{array}{l}\text { Dialogic Democracy } \\
\text { Recognition of equality of } \\
\quad \text { all participants. } \\
\text { Addresses power tensions }\end{array}$ & $\begin{array}{l}\text { Relational Responsibility: } \\
\text { Signal equality and facilitate } \\
\text { synchronization with } \\
\text { patient priorities and } \\
\text { reciprocal knowledge } \\
\text { building. }\end{array}$ & $\begin{array}{l}\text { Superficial-Dialogue: } \\
\text { Equality signalled but not } \\
\text { enacted as control of } \\
\text { conversation is held by one } \\
\text { dominant participant. }\end{array}$ & $\begin{array}{c}\text { Integration } \\
\text { of } \mathrm{HCP} \& \\
\text { Patient } \\
\text { priorities } \\
\text { Or } \\
\text { Domination } \\
\text { of HCP or } \\
\text { Patient } \\
\text { priorities }\end{array}$ \\
\hline Intellectual Honesty: & Room for Doubt: & Solution Promotion: & Integration \\
\hline $\begin{array}{l}\text { Allowing for a more } \\
\text { informed debate and } \\
\text { presence of non-expert } \\
\text { perspectives } \\
\text { Addresses perspective } \\
\text { legitimacy tensions }\end{array}$ & $\begin{array}{l}\text { Raise participant awareness } \\
\text { that 'truths' may be } \\
\text { challenged and encourage } \\
\text { direct questioning about } \\
\text { treatment and reflection. }\end{array}$ & $\begin{array}{l}\text { Limiting patient involvement } \\
\text { in discussion. Imposition of } \\
\text { clinician solution often as } \\
\text { 'expert advice' in abstract } \\
\text { or generic terms, the } \\
\text { opposite position to } \\
\text { personalisation. }\end{array}$ & $\begin{array}{l}\text { of HCP \& } \\
\text { Patient } \\
\text { concerns } \\
\text { Or } \\
\text { Domination } \\
\quad \text { of HCP or } \\
\text { Patient } \\
\text { concerns }\end{array}$ \\
\hline Affirmation: & Self-Expression: & Denial of Affirmation: & Integration \\
\hline $\begin{array}{l}\text { Demonstrating respect for } \\
\text { the realities of the other } \\
\text { and right to express } \\
\text { experiences and } \\
\text { emotions. }\end{array}$ & $\begin{array}{l}\text { Signal affirmation and } \\
\text { promote confidence for } \\
\text { open expression and } \\
\text { examination of experiences } \\
\text { and emotions. }\end{array}$ & $\begin{array}{l}\text { Only token recognition rather } \\
\text { than affirmation; blocking } \\
\text { of introduction of patient } \\
\text { emotional or negative } \\
\text { experience discussion. }\end{array}$ & $\begin{array}{l}\text { of } \mathrm{HCP} \\
\text { and } \\
\text { Patient } \\
\text { experienc- } \\
\text { es }\end{array}$ \\
\hline $\begin{array}{l}\text { Addresses } \\
\quad \text { socio-emotional } \\
\text { tensions }\end{array}$ & & & $\begin{array}{l}\text { Or } \\
\text { Suppression } \\
\quad \text { of HCP or } \\
\text { Patient } \\
\text { experienc- } \\
\quad \text { es }\end{array}$ \\
\hline
\end{tabular}

between the consumer and service provider, which we identify and define in terms of priorities, concerns, and experiences, during service interactions (Table 1).

\section{Co-creation and co-destruction mechanisms based on dialogic democracy}

The first principle, dialogic democracy, recognizes the equality of participants in dialogue and that all are subject to conflicts and tensions. Following Gergen et al. (2002), we argue that this principle can be translated into a cocreation mechanism through the interactional properties of (taking) relational responsibility to address power tensions. Supporting this, in the consultations we identified instances where relational responsibility was operationalized to promote dialogue towards equality, surfacing and acknowledging the priorities of each participant. Reciprocal knowledge building and the shared resource of mutual understanding of priorities is achieved through coordination of dialogue and synchronization of viewpoints that provide time and lag-time for dialogue and personalized exploration of meaning. Illustrating our identified co-creation mechanism of relational responsibility, we meet John (M, 65, Diabetes) in consultation with HCP7 (M, 42) where equality is initially promoted by a shared history, with HCP7 giving John space to explain his perspective on his questioning of his diabetes diagnosis and his priority of avoiding new medication is surfaced:

John: So then of course I tried to squirm out of taking pills by saying 'but it's only 7.3' and I said 'if you look on the Diabetic Association website, their range is up to 7 , so it's only a bit more than that' and he said 'but our range is 4 to 6 so you are over'.

HCP7: Yeah.

John: And he said [...] you're going to have to take pills eventually and the current thinking is that you might as well start taking pills alongside diet.

This represents a power tension within the dialogue, resolved when HCP7 synchronizes by integrating John's priority within his schedule for the consultation. 
HCP7: That's right, because you're on the statin aren't you already?

John: Yeah.

HCP7: And you're on XXX to keep your blood nice and thin [...] so if I just start from where I normally start from and then I'll know where to go from there.

HCP7 enables and co-ordinates a reciprocal knowledge building of the particular meaning of the diagnosis of diabetes in John's case. Reflecting the resolution of power tensions, John actively participates and interrupts to assess his understanding and add his reflections to the discussion. This allows the development of shared knowledge resources, where John's specific knowledge of his medical history is integrated with HCP knowledge, which continues as HCP7 then shares his perspective on the treatment of diabetes:

HCP7: So the whole thing with diabetes is we look at treating you as a whole ... things that we look are lifestyle changes $[\ldots]$ along with medication to keep your blood pressure lower [...] your cholesterol as well. So that's sort of what we're coming to.

This pattern repeats in the consultation, providing lag-time for both participants to return to and assess new knowledge. John is able to re-voice his objection to starting medication. A new, shared knowledge of each other's perspective emerges that HCP7 acknowledges:

HCP7: So we do tend to start treatment straight away. However, with an HbA1c of 5.8 and you're not overweight, we could say [...] right, we'll do your bloods in 3 months and 3 months after that to see where we're up to $[\ldots]$ not over-medicalise it.

However, equality is not easily realized within traditional power relationships, especially within complex services. Differences in consumer willingness and ability to adopt an equal stance and knowledge inequalities typically favor the service provider (Joseph-Williams et al. 2017; McCollKennedy et al. 2017). Our relational responsibility mechanism, outlined above, works towards reducing power tensions and aligning priority perspectives. Thus, we argue, a value codestruction mechanism can be theorized based on lack of resolution of power tensions, which reduces opportunities for knowledge resource sharing and represents competing priorities operating in conflict. In support of this conclusion, we observe interactions that seemingly invite one actor to share in dialogue with the other but were only superficially about their input and ultimately power tension resolution and shared resource building is minimal, what we label as the superficial dialogue mechanism. Below, Eliza (F, 46, Multiple
Conditions) is at a follow-up after biopsy with HCP2 (M, 37). HCP2 starts with a question to Eliza, but does not respond to the invitation to share knowledge in Eliza's answer "Ahhuh?" and moves swiftly to another topic without finishing the first.

HCP2: Hands on your head. You know we had excellent news about the result that we got after the biopsy? Eliza: Ah-huh?

HCP2: And I just want to read your ultrasound.

When Eliza tries to raises her priority of understanding the ultrasound results, HCP2 either gives no acknowledgement and continues with his agenda, or, as illustrated below, gives only a token echoing and remains in control whilst giving a short non- personalized explanation.

Eliza: It's probably scar tissue?

$H C P 2$ : Probably scar tissue but we will see you again in a couple of months' time.

[Eliza: $\mathrm{OK}]$ And then we make sure this has all settled down. [...] the good thing is that there's nothing obvious that we need to be concerned about. OK.

HCP2: So two months. [...] And if required we'll do an ultrasound but I will discuss this again in our specialist meeting to make sure that everybody's happy with this plan.

This does include a reassurance but it is termed as "expert opinion." It is also plain that any discussions or decisions on future ultrasound will not include Eliza.

Yet, patients are not dialogically powerless, and we also observe patients as 'reluctant' actors. They may not wish to integrate resources and so they too can demonstrate superficial dialogue, where they allow questioning but restrict their answers to those that develop their own agenda. In this example, we observe Margaret (F, 56, Breast Cancer) and $\mathrm{HCP1}(\mathrm{M}, 58)$ in a post radiotherapy follow-up consultation. Margaret declines the opportunity to share knowledge except to amplify that she has "no problems." HCP1 then offers an opportunity to discuss a shared history of treatment; but is met with only a short, token affirmation.

HCP1: Right then, how are you?

Margaret: I'm fine thank you. I've had no problems.

HCP1: Good. You've had radiotherapy.

Margaret: Yeah.

Over the consultation, Margaret continues to ignore HCP1's invitations for a coordinated dialogue beyond confirming 'concrete' issues and stressing "no problems," until it is clear she will avoid a repeat mammogram, when her relief is obvious in the "yes-plus" answer: "Oh that's good! That is brilliant." Subsequently it is clear that Margaret wished to avoid a procedure 
she found unpleasant and has shut down openings for dialogue to control information to circumvent further procedures (see Web Appendix for full example).

\section{Co-creation and co-destruction mechanisms based on intellectual honesty}

The principle of "intellectual honesty" (O'Leary 1985) requires making information accessible to a wider variety of social actors to allow for a more informed debate to support value creation (Payne et al. 2008). Within health services, we argue for a cocreation mechanism that raises participant awareness that medical "truths" can be questioned, what we term room for doubt. During this consultation between Jim (M, 61, Prostate Cancer) and HCP15 (M, 49) we observe instances that constitute the conditions for enabling of transparency and accessibility of information, whilst acknowledging the possibility of not knowing or being wrong, thus enabling reduction of tension between expert and lay perspectives ultimately leading to a shared resource of understanding of the meaning of treatment. HCP15 begins by implicitly and explicitly inviting Jim's participation. He provides room to share perspectives and concerns by offering an informed choice to Jim and opening discussion. There is an in-depth knowledge exchange, with HCP15 explaining the options and disclosing competing opinions on treatment efficacy versus side effects, that is, room for doubt. Jim demonstrates direct questioning and learning:

HCP15: So those are the options [explanation of options] What you're choosing are what side effects [deeper explanation of treatments and side-effects] what convenience or inconvenience you would accept as part of that procedure.

Jim: OK, so we're looking at treatment at some point, reasonably minimal side effects?

HCP15: Yeah -

Jim: I mean I expect problems from the passing of water, etc.

HCP15 explains his perspective that choice is about balancing risks between side-effects and effective treatment within Jim's specific context, thus allowing further room for doubt in treatment choice risk implications.

HCP15: If surgery's right for you, that's great, but if they try and preserve the nerves then $[\ldots]$ there is a risk that they can leave cancer behind. [...] You would need to have radiotherapy on top of your surgery, but you then get the side effects of radiotherapy as a combined -

$\mathrm{Jim}$, however, voices his perspective that his concern is for his health rather than side effects. HCP15 aligns with this in discussing future options rather than further side effects. Jim again demonstrates integration of new knowledge and emergence of new understanding as he reflects openly on the acceptance of some responsibility for risk demonstrating the emergence of a reciprocal and patient-centered understanding of Jim's condition severity and treatment options, integrating the patient perspective into the medical discourse.

Jim: I go for the health before anything else.

HCP 15: Sure. Now one thing [...] if you go for radiotherapy $[\ldots]$ you can't then have your prostate removed [discussion of implications of choice for future options]. Jim: Right. [...] I was left, knowing that as the patient I have to make the decision. I think my avenues are active surveillance for 3 months. If it goes up, radiotherapy.

It follows that reducing these opportunities also reduces value creation possibilities. In support, our data revealed instances that contrast with such transparency, accessibility of information and room for doubt. We label this mechanism solution promotion, which inhibits integration of the patient's perspective and concerns on conditions and treatment into the discourse. Or, when enacted by the patient, this mechanism imposes the lay voice and similarly closes down discussion. In this consultation with Tom (M, 67, Prostate Cancer), HCP10 (M, 45) maintains control and dominates the conversation with little open discussion of options or room for Tom's perspective on his treatment concerns to be considered.

HCP10: OK. Well I think that's something which we could offer you - an operation to enable you to pass your water better [discussion of operation] I don't want to make a definite decision about doing that operation for you yet -

Tom: OK.

HCP10: The way I think it will go is that we'll do that operation, and then we'll watch and see [...] If needed we can then go ahead and give you radiotherapy but, if we found (cancer) in the bone [...] we'd be doing a different approach [...] with hormone tablets ... I really don't think that's we're going to find which is why I've not laboured that.

Presented as expert advice given in generic terms, the opposite position to personalization, this is very much in a one-way, (medical) information script offering a specific solution with reference to personal expert preference (I'd like; I (don't) think; the way I think it will go) backed with medical justifications. Note the immediate repeat of the preferred solution by HCP10. Tom does, however, try to raise a concern and questions the HCP.

Tom: Um, it's possible to, er, check out if there is cancer while you're in the operation? 
HCP10: Yes, all that tissue would be checked as well. So that gives extra information.

Tom: Yes, yes, yes. Thanks, I think, er, if that's possible that would be really ideal.

Tom's question receives a direct answer, demonstrating integration of knowledge resources but the context is within the offered treatment pathway, not the choice of pathway. HCP10 then takes control again by asking for approval of the preferred strategy in terms that nominally ask the patient opinion but are hard to dispute. This in effect imposes the expert opinion, a specific treatment pathway, and closes down discussion with a relative lack of questions from the patient about their personal perspective on concerns and implications.

HCP10: Yeah. OK, you obviously understand very well I think?

Tom: Yeah -

HCP10: Have you got any more questions or anything?

Tom: No, no, no, no, I understand everything you say.

\section{Co-creation and co-destruction mechanisms based on affirmation}

The principle of affirmation requires each party to demonstrate mutual appreciation of realities and experiences, representing opportunities for both new understandings and for emotional maturity with value beyond adherence to treatment regimens. Critically, acknowledgment of patient affectual experience can reduce the extent to which these disrupt the patient's role in dialogue (Gergen et al. 2002). It relieves tensions and uncertainties, and it helps patients to effectively engage with decision making, treatment, and day-to-day coping and, thus, can contribute to value co-creation (Grönroos and Voima 2013). A cocreation mechanism based on this principle, we argue, requires acknowledgment of the legitimacy of a person's experience, especially socio-emotional aspects. Our data evidence a selfexpression mechanism whereby patients achieve recognition of the legitimacy of their experiences, especially (amongst a wide range of emotions) their anxiety and frustration. We observe HCP13 (F, 52) acknowledging the frustration posed by Thomas (M, 76, Multiple Conditions) about lack of information, facilitating a (re)alignment of dialogue and integration of the patient experience that surfaces his continued worries regarding treatment outcome.

Thomas: This is another thing that annoyed me about all this; we've not had any information about what the diagnosis was or anything.

HCP13: OK. What do you want to know?

Thomas: All I want to know is how long am I going to live?
HCP13: Right, the idea of giving you this treatment is to try and cure you.

Thomas: Oh, so this is a cure?

HCP13: This is to try to cure you.

Thomas: Oh right, that's good.

We observe that HCP13 implicitly acknowledges the legitimacy of the worry accordingly aligns the discussion and explicitly introduces the idea of the treatment as "cure." Thomas reflects on the meaning of HCP13's statement and indicates integration of new knowledge. HCP13 goes on to clarify the meaning of "cure" in the specific clinical situation of the patient.

HCP13: As I said, it's a balance between how risky things are and how aggressive we want to be - So, it's this balancing act between how we're hitting the cancer and how we're hitting you. [a discussion of radiotherapy as it relates to the patient]

Thomas: So, what's my general prognosis?

HCP13: Well it's difficult to -

Thomas: Am I going to die tomorrow?

HCP13: NO.

Thomas: Oh right! [laughing]

We see Thomas has the confidence to engage in dialogue to return to and openly express his worry about how long he will live. The direct, emphatic and assertive answer "NO" from HCP13 matches the intense question from Thomas. This affirmation seems to resolve the tension, as in his answer Thomas indicates acceptance and new understanding, with a laugh.

Not providing affirmation to allay negative emotions may lead to greater risks of confusion about outcomes and potential for co-destruction of value in service delivery (Plé and Cáceres 2010). We label this mechanism denial of affirmation. Whether from HCP or patient, this shuts down dialogue and effectively destroys opportunity to reduce tension and share perspectives and preserves the burden of emotion in dialogue. Below, we observe this negative counterpart, where the legitimacy of experience or worries is not acknowledged, often actively "normalized," which blocks attempts to integrate experience into the dialogue. Stephen (M, 61, Prostate Cancer) (implicitly) expresses his anxiety about the unexpected (to him) aftereffects of a biopsy for cancer diagnosis. HCP9 (M, 42) interrupts with a reply that while in part reassuring, is also a denial of the legitimacy of any anxiety. Stephen's determined rebuttal indicates the tension between perspectives.

Stephen: And there was quite a bit of blood in the urine 
HCP9: That's normal.

Stephen: But you know, I don't know what's normal and what isn't and it sort of fooled me because - well, it came out blood first and then the urine.

Stephen then tries to re-introduce his anxiety and is given some space to enlarge on the symptoms but, as we see below, HCP9's reply, "Obviously, I'm sure they told you before," is another "normalization" response, framing the experience as a foreseeable event and constitutes denial of affirmation.

HCP9: OK. Obviously I'm sure they told you before that there's about a 1 in 100 chance of getting an infection.

Stephen: Yes, they did.

HCP9: Obviously it's not ideal handling when you came back into hospital. [...] Have you done a urine sample today at all?

Stephen: I didn't, no.

HCP9: You might just at the end have a urine sample

[...] we'll chase that up at the end.

Stephen: Yes.

HCP9: OK, so a horrid time following on from the

biopsies. We've had a look at the results [...]

Further, this is combined with solution promotion in the offer of a urine sample followed by a "token" recognition of Stephen's experience ("so a horrid time") as a "wrap-up" and indication of the end of the topic and a swift change of direction back to HCP9's consultation itinerary.

Patients also seem to resist opportunities to express worries despite HCPs attempting to elicit experience sharing. In this extract, despite the unfolding of the severity of side effects and extra enquiries from $\operatorname{HCP} 6(\mathrm{M}, 49)$ who seems willing to discuss these, Lisa (F, 50, Breast Cancer) reacts only with a short response token and no verbally expressed emotion:

HCP6: Side effects with chemotherapy, tiredness, you lose your appetite, vomiting, diarrhoea, mouth sores, loss of hair and your blood counts become low. [...] All right?

Lisa: Ah-huh.

The pattern repeats as HCP6 continues an increasing revelation of the extent of the effects.

HCP6: It can also cause pins and needles and you may get swollen ankles as well.

Lisa: OK.

HCP6: So it doesn't sound too clever [...] Different people have different side effects... but I think things like hair loss is probably unavoidable and getting tired.
Lisa: Right.

HCP6 continues to offer chances for discussion but essentially, meets only token or "closure" answers, except regarding "concrete" physical issues. Lisa finally asks a question that (in part) reveals her priority: "It's things like when can I go back to work?" HCP6 aligns with Lisa and discusses this but as Lisa does not share the reason behind the question, the information exchange is mostly one-way from HCP6 to Lisa and the tension is not fully resolved (see Web Appendix for full example).

\section{Part 2: Conceptualizing longitudinal value for complex services}

For complex services like healthcare, value is challenging to define and operationalize (Sánchez-Fernández et al. 2009). Current value conceptualizations in health services research, such as quality of life (McColl-Kennedy et al. 2017), try to capture consumer-centeredness, but are often implemented as measurable service delivery parameters. Yet consumercentered value is better reflected in terms of the psychosocial adjustments of patients' lives, which are not necessarily or directly aligned to medical values or readily structured or measurable in a professional delivery sense (Kent and Taylor 2018). Accordingly, as a basis for our understanding of value within health service interactions, we adopt Holbrook's multifaceted conceptualization of consumer value, which has high relevance to complex services (SánchezFernández et al. 2009). Integrating this framework with DE theorizing on value, we argue for three conceptual components of value within complex services.

First, value is multi-dimensional, and multiple values can exist within any one consumption experience. Holbrook (1999) discerns eight types of value: efficiency, excellence, status, esteem, play, aesthetics, ethics, and spirituality. The multiplicity of value emerges as consumers experience consumption, aligning with the DE view that value arises from interactions (Kent and Taylor 2018). Thus, meaningful value develops in relation to the goals that consumers attempt to achieve during interactions (Martela and Steger 2016). For health services, the myriad of goals relevant to consumers of complex services likely lead to the emergence of multiple values within complex service interactions.

Second, value is dynamic, not isolated to single interactions but developing across time (Holbrook 1999). At its core, DE is inherently longitudinal, has history, context and culturally shaped norms, and value dynamically emerges over multiple interactions (Cissna and Anderson 2012; Kent and Taylor 2018). Nascent research on the longitudinal aspects of co-creation (see Table 2) recognizes these temporal aspects (Chandler and Lusch 2015; Razmdoost et al. 2019), suggesting that value processes are 
Table 2 Marketing literature concerning longitudinal value co-creation

\begin{tabular}{ll}
\hline Authors & Primary focus \\
\hline Payne et al. 2008 & $\begin{array}{l}\text { B2C/B2B: A conceptual framework for } \\
\text { understanding and managing value } \\
\text { co-creation in the context of S-D logic }\end{array}$
\end{tabular}
Helkkula \& Kelleher,
2010

Mele, 2011

Ritala \& Tidström, 2014

Chandler \& Lusch, 2015

Jaakkola et al. 2015

Banoun et al. 2016

Beirão et al. 2017

Hollebeek et al. 2019

Razmdoost et al. 2019
B2B (A2A): Evolution of service systems. Case studies of five IT shared services centers and internal clients

A2A: Value cocreation in service ecosystems: Investigating healthcare at the micro, meso and macro levels

C2B: Application to CRM of integrative framework for S-D logic-informed customer engagement

2B: customer service experiences and customer perceived value related to iPhone service experience

B2B: the nature of conflicts and their influence on value co-creation in global IT organization project networks

C2B: a systematic characterization of value in the experience, with narrative analysis example

B2B: Exploratory longitudinal case study of four Finnish manufacturing firms

A2A: Service systems framework on value propositions, engagement, and service experience

\section{A2A: Conceptualizes service experience} co-creation

B2B: Managing interdependencies between past, present and future project co-creation activities
Main contribution

Customer value-co-creating process is a recursive, goal-orientated interconnected set of interactive processes. Customer experience drives learning/evaluation influencing future activities.

Customer co-creation is a circular complex perceived value process where customer's past experiences influence present expectations and experience, affecting future interactions.

Positive/ negative conflict promotes/hinders co-creation by allowing/ blocking different perspectives/dialogue and shared understanding. Over time, this strengthens / reduces value co-creation opportunities.

Identifies: 1 . the influence of real/ imaginary value experiences on present service experiences in an iterative circular sense-making process, 2. past experiences of value can be re-evaluated at future time points.

Conceptual framework of value creation in coopetition. Over time, value creation objectives change, often through wider stakeholder influence.

A temporal connection is related to present day meaning making emerging from past experiences and oriented towards future experiences. Actors influence each other through continuously evolving relational connections.

Customer real/imagined experiences create expectation and evaluation loops between past, present and future interactions and value co-creation

Service systems evolve around phases of tensions and solutions. Over time service ecosystem relationships broaden from dyadic-dominant relationships, to all the actors of the complex network

Co-creation factors (resource access, sharing, recombination, resource generation) enable actors' resource integration across multiple interactions to co-create population and ecosystem value outcomes

Customer co-creation linked to customer interpersonal operant resource development. In turn linked to iterative process of customer resource integration, knowledge sharing and learning.

Conflict is often trigger for co-creation processes, but value co-creation processes and mechanisms used are recursive, and oriented towards management of future value co-creation activities
Type of paper

Conceptual \& application of framework

Empirical narrative study

Multiple project Case study

Conceptual \& empirical example

Conceptual and empirical

Conceptual

Conceptual

Empirical

Case study

Empirical

Interview

Conceptual (with panel consultation)

Empirical, Case studies circular and volatile. Circular, as successive experience of resource integration (or not) and subsequent cognitive evaluations have consequences for future interactions (e.g., Payne et al.
2008). Volatile, because meaning ascribed to an experience is situationally driven and subject to re-evaluation with any change in context or priorities (e.g., Helkkula et al. 2012). This dynamic 
view of value is relevant to the typical complex service involving multiple actors extracting value (or not) across multiple interactions, often within the bounds of predetermined service conventions and with, sometimes dramatic, context changes (Keeling et al. 2019).

Third, the shared nature of value is crucial to value co-creation. This is less developed in Holbrook's framework, but it is essential in DE. For DE theorists, value emerges from a mutual transformation process towards a critical, shared meaning. As an ideal, actors share the process of value development over multiple interactions, where value is fluid without a defined 'end outcome' (Bebbington et al. 2007). Instead, value is defined as the development of capital to enable transition from a naïve understanding to a critical and mutual shared meaning between actors (Kent and Taylor 2018). We argue that shared meaning is both a value in itself and enables other values to be extracted (e.g., in making shared decisions about treatments). Yet DE theorists are clear that critical stances are difficult to achieve and may never be realized. Services marketing research also notes the limits on co-created value achievement as professional providers are bounded by objective professional judgment and ethics (e.g., Aarikka-Stenroos and Jaakkola, 2012). Further, the success/lack of conflict resolution between actors has latent amplification effects over successive interactions, with a lot of room for misalignment between actors in health services delivery, and potential for both value cocreation and co-destruction (Keeling et al. 2019; McCollKennedy et al. 2017; Mele 2011). We argue that the interactive and relativistic nature of value is important here (Holbrook 1999). For example, in consultations patients and professionals may interact with each other and/or with the focal condition. At the same time, their developing understanding of treatment choices may be grounded relative to their personal or service perspectives.

In the next section, we establish the values being co-created/destroyed in dialogue and how value emerging at one time point morphs over subsequent interactions facilitated by mechanisms and resource (non-integration). We take into account (1) the multidimensional nature of value, demonstrating that each mechanism enables the co-creation (or codestruction) of different values, (2) the dynamic nature of value explaining how these multiple values dynamically evolve over time, and (3) the shared nature of value, where, over time, values evolve into shared value between the HCP and patient.

\section{Dynamic value co-creation through dialogue engagement}

\section{Co-creating the value of "efficiency"}

We observe that during initial dialogue between HCP and patient, the mechanism of relational responsibility enables the value of efficiency to be co-created. Holbrook's original conception of efficiency is the value resulting from the "active use" of a product to achieve a personal goal. We identify efficiency here as referring to service efficiency in the shape of the patient's own treatment pathway. For example, Frank (M, 65, Prostate Cancer) in consultation with HCP8 (M, 51) begins by querying the service efficiency. In response to Frank's specific questions, HCP8 explains the problem and offers insight into the treatment trajectory. What emerges is an initial co-creation on the value of service efficiency.

Frank: One query I'd got was if the radiotherapy is not successful, am I right in thinking that surgery is then ruled out?

HCP8: We wouldn't recommend surgery after radiotherapy [explanation of risks] treatment would be high intensity focused ultrasound treatment [...]

Frank: Is there much damage in the surrounding area?

HCP8: [...] effectively there will be some damage [...]

Frank: Right. [...] So last question, prognosis? [laughing]

HCP8: [...] you've got more chance of being cured than not. $[\ldots]$

Frank: [...] my priority is get rid of it. If as a consequence I'm impotent and incontinent, so be it. Radiotherapy, the chances of incontinence are fairly low and presumably impotence is $[\ldots]$

At subsequent consultations, we observe that the value of efficiency evolves into relevance. That is, relational responsibility continues to facilitate a challenging dialogue where both parties come to an understanding about the personal relevance of the efficiency of the service. In the extract below, we observe Jeremy (M, 70, Multiple Conditions) feels able to raise a query about his cancer severity. HCP10 (M, 45) accommodates this by asking, "What did they say?" and they discuss the possibility of this specific cancer re-occurring. They come to a shared understanding of the personal relevance of likely treatment if this were the case.

HCP10: You had the most advanced form of cancer $[\ldots]$ it's gone a bit more than what you would normally expect ... [some discussion] ... the worst case scenario is if it comes back what do we do at that point? I doubt we can do another operation.

Jeremy: No, no.

HCP10: It will be hormone treatment I think.

Jeremy: Yeah, that's what I think. Injections in the tummy.

HCP10: Yeah, injections every three months.

In later dialogue, efficiency remains important and, we observe, has the potential to develop into critical exchange. This value develops beyond Holbrook's original active use of the 
service to, consistent with DE, a deeper, critical, and mutual appreciation of service efficiency. Thomas (M, 76, Multiple Conditions), at the end of his treatment, has developed an interest beyond his own care. Dialogue goes beyond the boundaries of his own treatment, including knowledge about new treatments, and he and $\mathrm{HCP} 12(\mathrm{~F}, 50)$ are able to debate more equally.

Thomas: Because, yeah, because, obviously, when I was diabetic, you read all the booklets and you think, well your legs are going to drop off -

HCP12: Yeah, yeah. And don't do too much on the Internet either, so! [...] It is really good and most people are very much aware of things [...] it's just confusing $[\ldots]$ and they think, I would like this treatment, and it's not actually a treatment today, so.

Thomas: What's that one that they've just spotted, just recently -

HCP12: The medication?

Thomas: Within 10 years -

HCP12: No, 3 years.

Thomas: Is it 3 ?

HCP12: It's going to be available in 3 years [...] and it's nice to read about them, and then we can discuss it here, so, I mean, next time - [discussion continues]

Thus, efficiency as it relates to the service emerges as an important value, but its nature develops over time, and critically it becomes a shared value between the HCP and patient. Through DE, value development is underpinned by dialogue that allows patients to integrate HCP knowledge into their own learning. Patients may persist with pursuit of important priorities but with greater knowledge and confidence in taking part in the dialogue. What results is a mutually validated understanding of the management of the condition, not just with a personal focus but with a holistic, critical, shared understanding.

\section{Co-creating the value of "excellence"}

Initially, we observe that the "room for doubt" mechanism allows the patient and HCP to utilize the professional excellence in meaningful dialogue. Echoing Holbrook's (1999) notion of excellence as a "reactive appreciation" of another's ability to help address a need, professional excellence is valued as it enables dialogue to address specific concerns. Jim, (M, 61, Prostate Cancer) uses the opportunity to seek further development of shared resources with and HCP15 (M, 49) to check his concern about his prostate cancer spreading:

Jim: Right. [...] Now the only thing, the other grey area I thought of how will they ever be able to check that the cancer has spread?
HCP15: Um, it's very difficult. Your numbers, the PSA, predicts that you've got a very low chance of the cancer having spread [...] If I do a scan [short explanation] Jim: So we're looking at a reasonable picture.

HCP15: Absolutely. If your PSA was 20 you've got about a 2-3\% chance that there would be cancer in the bones. If your PSA was 50, then you've got a $50 \%$ chance.

Jim: Obviously the higher the PSA, the higher the risk.

In later dialogue, professional excellence develops into proficiency acknowledgement by both HCP and patient. That is, a shared value is emerging of the excellence that each person brings to choice decisions. For example, at the end of the following extract, there is implicit acknowledgement by HCP11 of Edwards's ability to weigh-up the risks of different treatment options demonstrated by the agreement between them.

Edward: $[\ldots]$ the PSA was running at 9 and that's how they picked it up but I mean [...] I'd got no symptoms that one would normally get.

HCP11: [...] patients who come with symptoms, usually the prostate cancer is more advanced [...]. So the fact that you only found out on the blood test is a good thing $[\ldots]$.

Edward: Well I mean that's right, and it was by talking to Dr X, because I was going to think in terms of active surveillance and not doing anything, but Dr X suggested that radiotherapy was perhaps a $75 \%$ chance of knocking it on the head at this stage.

HCP 11: Absolutely.

Edward: And probably I wouldn't have any more trouble for the rest of my life, so I thought well those are odds that I can tackle. [...] and [...] I think that's a good idea. HCP11: I'm happy with that.

Later, the excellence value develops further emerging as shared appraisal. That is, there is an enabling of genuine and explicit debate within the dialogue. For example, Elizabeth (F, 46, Multiple Conditions) and HPC7 (M, 42) debate the pros and cons of an alternative treatment that Elizabeth introduces:

HCP7: We do tend to leave you on [...] with insulin $[\ldots]$ it does help to curb weight gain.

Elizabeth: I went on, ooh a diabetes programme - and they mentioned some sort of artificial insulin that didn't have the weight gain [...] I can't remember what it was now. HCP7: Lizard spit they call it [...] it acts on the satiety centre in the brain $[\ldots]$ it's in its very early stages [gives account of various reactions]. Um [...] if you wanted to try - 
Elizabeth: I'm not sure about the, you know, the hunger and satisfaction thing, because I eat when I'm bored, not when I'm needing to eat, if you see what I mean.

HCP7: Right. I mean, this particular drug has some side effects to it [...] you'd still be injecting twice a day [...] the companies say that the feeling of sickness is only transient.

Elizabeth: But it's worn off [...] Is it possible to consider that after going on insulin?

HCP7: Yes, yes, it is [...] so it's very individual [...] I would suggest that you start the insulin and see how you go on that, you may not gain any weight $[. .$.

Elizabeth: Oh Sxx’s Law says I will!

The value of excellence begins with a focus on professional excellence, but over time that combined value of HCP and patient excellence is increasing acknowledged. That is, it develops beyond the "reactive appreciation" of another's excellence (as per Holbrook) to what we see as active appreciation of both parties' excellence. Where room for doubt operates in earlier consultations, then patients may continue conversations during later consultations on the issues discussed, gaining further co-created value by applying the learning about personal meaning to sense-making of the treatment and outcomes. For example, patients are able to evaluate their progress and take ownership of aspects of care (e.g., exercises after surgery). In some cases, this was linked to adherence, though not always. For example, we observe at least one patient using 'room for doubt' in justifying lack of adherence to treatment. What results is a mutually validated justification of the choice(s) made and associated risk(s).

\section{Co-creating the value of "esteem"}

In early dialogue, we observe the importance of the value of esteem, enabled by the self-expression mechanism. For Holbrook, esteem is a "passive" appreciation of one's own means to build a "reputation" with others. The "means" in our case refers to a patient's socio-emotional experiences. While patients actively assert these experiences, they passively appreciate them by seeking professional esteem through positive acknowledgement and reassurance from the HCP. For example, Thomas (M, 76, Multiple Conditions) and HCP11 (M, 61) discuss Thomas's anxiety with the diagnosis, ending with Thomas reassessing the personal meaning of his condition (repositioning his earlier doubt as pessimism).

Thomas: [...] So, like I said, I'm fine, great, no problems, $[\ldots]$ then I got the little letter that you sent me $[\ldots]$ about the lymph nodes [...] And I thought 'God [...] HCP11: I apologise if I've caused you any distress [...] what I said last time is going to be true $[\ldots]$ if they were cancer, your PSA would be 80 or 100 and it was 18.1
[...] when you get prostate cancer [...] spreading people come with PSAs of 80, 150, $200-$

Thomas: Oh, I see, yeah.

HCP11: And yours was 18.1. [Thomas: Hmmm.] And we all work on the experience that we've had over the years that if the PSA is under 20, it's almost certainly not spread. [Thomas: Hmmm.] And that's why I still believe this is the result of the biopsies and I believe I might be giving you the good news that you want in May.

Thomas: I won't, I'm a bit of a pessimist anyway, erm [short discussion]

HCP11: But please be reassured there's, I'm sure I'm right.

Thomas: Thank you very much indeed.

During later consultations, we observe a development of the esteem into affirmation, with a mutual expression and recognition of emotional vulnerabilities. In this extract, HCP11 openly expresses his own relief, Thomas is confident in self-reflection.

HCP11: There has been almost complete resolution of the extensive haemorrhage $[\ldots]$ The conclusion $[\ldots]$ a $\mathrm{T} 2$ tumour $[\ldots]$ which means you're going to be OK.

Thomas: Oh, fantastic!

HCP11: All right?

Thomas: Yeah, I've been waiting for two months to hear that! [laughing]

HCP 11: I know and I just got this - I've been away for a week and I just got this on my desk the day I got back, which is why I phoned you. [...]. But it's terrific. [...] Thomas: You know you start thinking of all sorts of things but that's great. Because I did say last time, you know, there was an average chance now with the prostate.

HCP11: Oh, very much. More than average. Better than average. [...] I mean we were all so delighted because it was relief [...] there's no spread to the bones.

Thomas: Fantastic. [...] You're a smashing doctor! [laughing]

Later, as the self-expression mechanism continues in dialogue, we observe affirmation evolving into mutual respect. In the example below, Frank (M, 65, Prostate Cancer) and HCP8 (M, 51) discuss and acknowledge their different contributions and delight and worry.

HCP8: The hard bit is the bit that you do. My bit's always the easy bit. [laughing] Because the hard bit I always find is the recovery and the rehabilitation, so I tend to get the cancer out the way and so yeah, the cancer, we're delighted with that, fantastic and then say how are you doing with yourself really, waterworks wise and the like? 
Frank: I feel fine. Waterworks, rubbish. [...] We've gone through a series of total shock. I don't think I appreciated what incontinence meant, which is probably just as well actually. Absolutely awful. The problem I've had is I've been doing the exercises because I don't want to be one of your percentage failures you see.

HCP8: That's all right.

Frank: So I don't know whether I get a bonus at the end or you get a bonus!

HCP8: Oh you get the bonus! [laughing]

Frank: But it's so difficult to know whether you're making any real improvement - and I am just beginning to notice things.

Frank is then able to talk openly about his experience that came as a "physical shock and a psychological shock" which HCP8 acknowledges and supports as a "long slow process":

HCP8: But we know it gets better with time and the exercises.

Frank: Yeah.

The value of esteem develops in dialogue over time from a recognition of the patient emotions through to a mutual respect between HCP and patient. The passive appreciation of Holbrook's original conceptualization of esteem, evolves to a mutual appreciation of each other and a willingness to expose their vulnerabilities. We also observe indications of developing positive relationships, where both $\mathrm{HCP}$ and patient share personal information. What results is a mutually validated understanding of the socio-emotional context within which the patient and the HCP operate, and that both are subject to vulnerabilities.

Consistent with our multidimensional, dynamic view on value, efficiency, excellence and esteem are progressively co-created across interactions. This is facilitated by the proposed co-creation mechanisms, with each iteration of value contingent on the value created in prior interactions. We observe that over time the nature of value progressively develops in terms of: (1) depth of understanding (from a local to a global, multi-perspective view) and (2) becoming increasingly shared between parties (Table 3 ).

\section{Dynamic value co-destruction through dialogue engagement}

\section{Co-destroying the value of "efficiency"}

In early dialogue, with the use of Superficial Dialogue, we observe the value of efficiency as it relates to the service emerging, as we did with relational responsibility. However, rather than dialogue bringing the $\mathrm{HCP}$ and patient to a closer understanding, this value is experienced differently by the actors. In the following extract with $\mathrm{HCP} 2(\mathrm{M}, 37)$ and Rose (F, 72, Multiple Conditions), for HCP2 treatment efficiency is valuable. For Rose, although she benefits from the progression of diagnosis and identification of treatment, the lack of integration of her priorities, for example, Rose's difficulty with moving her arm, may be construed as destruction of the potential value of meaning. Rose is unable to 'actively use' the service to achieve a personal goal.

HCP2: OK, then it did, OK - and in terms of any difficulty in moving your arm?

Rose: Well I have had [...] quite a lot of difficulty, I have been climbing up the wall.

$H C P 2$ : Climbing up the wall, $\mathrm{OK}$ good, and have you been making progress?

Rose: Yes, it is getting better and I have fallen, which is why this arm isn't very good, [...] it was hurting quite badly, but now when I massage it I can touch it [...]. HCP2: OK. Have you been given a booklet about the radiotherapy?

Rose: No.

HCP2: No? The book where they explain about the markings and all the tattooing?

Rose: No.

When superficial dialogue persists, we observe a pattern of dominance resulting in a separation between the HCP and patient. In contrast to the value of relevance that we observed with relational responsibility, though the patient may question the service, there is a distancing from the self to focus on more concrete, non-personal issues, such as frequency. This does not imply that personal relevance is not important, rather that initial dialogue can set the tone for subsequent dialogue. Below, Elizabeth (F, 46, Multiple Conditions) carries forward her priority from the last consultation of understanding the mammogram in challenging and gaining her objective. But HCP2 does not acknowledge Elizabeth's urgency.

HCP2: [examination]. I didn't feel anything to be honest.

Elizabeth: No.

HCP2: Perhaps I think we should do another ultrasound at some point.

Elizabeth: Is it not possible to do it today?

HCP2: Erm, it won't be three months yet.

Elizabeth: Only since the last time? [...] It was the 2nd June.

HCP2: Three months then. So perhaps we should repeat a scan again to see this lumpy area that we saw, possibly on the repeat scan it's possible it's just a scar.

Elizabeth: Yes, but [radiologist] wasn't happy to declare what it was at the time. 
Table 3 Describing longitudinal co-creation and co-destruction of value

\begin{tabular}{|c|c|c|}
\hline \multirow{6}{*}{$\begin{array}{l}\text { EFFICIENCY } \\
\text { VALUE }\end{array}$} & \multicolumn{2}{|c|}{ Co-creation pathway - the evolution of efficiency value } \\
\hline & Service efficiency & Relevance \\
\hline & $\begin{array}{l}\text { The 'active' use of the } \\
\text { service by both actors in } \\
\text { terms of its ability to } \\
\text { deliver on their dual } \\
\text { goals in the treatment } \\
\text { pathway. }\end{array}$ & $\begin{array}{l}\text { Concerning the application } \\
\text { and fit of the service to } \\
\text { the person's individual } \\
\text { nuances of condition. }\end{array}$ \\
\hline & \multicolumn{2}{|c|}{ Co-destruction pathway - the deterioration of efficiency valu } \\
\hline & Treatment efficiency & Separation \\
\hline & $\begin{array}{l}\text { The 'active' use of the } \\
\text { service by one actor in its } \\
\text { ability to treat the } \\
\text { condition. The other } \\
\text { actor's goals are } \\
\text { neglected. }\end{array}$ & $\begin{array}{l}\text { Establishment of medical } \\
\text { dominance, distancing } \\
\text { concrete treatment value } \\
\text { from person value. } \\
\text { Neglecting individual } \\
\text { nuances of condition. }\end{array}$ \\
\hline
\end{tabular}

EXCELLENCE Co-creation pathway-the evolution of excellence value VALUE

ESTEEM VALUE cerns.

Co-destruction pathway - the deterioration of excellence value

are not incorporated. treatment pathway.

Co-creation pathway - the evolution of esteem value

\section{Professional Esteem Affirmation}

\section{Critical exchange \\ A shared deep, analytical critique, and mutual appreciation of the global efficiency of the service to the focal condition.}

\section{Withdrawal}

The value to one actor is retracted and the other actor pursues their own agenda in relation to service value. Focus is confined to the specific treatment level.

\section{Shared appraisal \\ An 'active' use of the excellence of both parties in enabling genuine and explicit debate of the condition/service.}

$\begin{array}{lll}\text { Deterministic excellence } & \text { Rigidity } & \text { Exclusion } \\ \text { The value of professional } & \text { Professional knowledge } & \text { Total reliance on } \\ \text { knowledge and merit lies } & \text { and merit define the } & \text { professional excellence } \\ \text { in validating the } & \text { boundaries for a strict } & \text { in interpreting the } \\ \text { HCP-determined } & \text { reliance on professional } & \text { outcome, neglecting } \\ \text { choices. Patient concerns } & \text { determination of the } & \text { patient excellence. }\end{array}$

Patients actively assert their A mutual expression and experiences, but passively appreciate them by seeking positive acknowledgement and reassurance from the professional.

Co-destruction pathway - the deterioration of esteem value
Professional Indifference
Patient socio-emotional ex- periences are neglected, limiting the possibility of esteem.

\section{Mutual respect \\ Shared appreciation of each other's personal worth and a willingness to actively expose vulnerabilities.}

HCP2: Yeah, so perhaps we'll repeat your scan. [...] I'll request another one today.

During later dialogue we observe that separation settles into withdrawal. That is, the patient is observed as withdrawing and not engaging with the dialogue and the professional is happy to continue with their own agenda. As directly stated by Rose:
HCP2: OK, excellent. OK, anything else from your side?

Rose: No, I can see that as things happen I will know more about it.

When superficial dialogue ensues the value of efficiency is destroyed over time. That is not to say that the efficiency of 
the service is eroded, rather the efficiency value to one or other of the actors is eroded. As such, the opportunity for a mutually validated understanding of the management of the condition erodes and the consumer-centered focus is gradually lost over time. In such cases, the patient effectively withdraws from participating in the dialogue or only operating at minimally sufficient levels.

\section{Co-destroying the value of "excellence"}

In early dialogue, the value of excellence again emerges, but through solution promotion, not in a way that engages the patient's concerns. Professional excellence instead emerges as a deterministic excellence that validates the HCP-determined choices. Below, in the dialogue between Tom (M, 67, Prostate Cancer and HCP10 (M, 45), who we met earlier, Tom's perspective is not effectively integrated, rather relying on the excellence of medical procedures to determine the pathway.

HCP10: So I think the plan is that if the bone scan is clear [outlines possible options] so the bone scan's fairly critical into which direction we go. [...] we should probably speak a little bit more with the results and we can explain it honestly. We can't do everything on an 'if we do this we'll do that'. Is that all right with you?

Tom: That's fine.

HCP10: So let's get you back in the clinic next week.

Tom: OK, so you don't need to see the other experts for

HCP10: [interrupts] So let's get the bone scan, if we can get you back next week and take it from there.

As Tom discusses his scan with HCP13 (F, 52) directly following, it is clear that the value of the dialogue lay in confirming the professional perspective, rather than Tom's own.

HCP13: I'm just going to go through your consent procedure [...] Has [HCP10] explained much to you at all about the procedure?

Tom: Yes, he's given me a leaflet. [...] Which seems to be confirming what he's said.

In subsequent dialogue, we observe that excellence morphs into rigidity. Rather than a converging of professional and patient excellence (as we saw with room for doubt), the value of dialogue remains reliance on professional determination of the pathway. This is explicitly recognized by Stephen $(\mathrm{M}, 61$, Prostate Cancer) in dialogue with HCP9 (M, 42).

HCP9 [repeating the solution]: But first is the bone scan and probably an MRI scan and see where we go from there.
[The pattern repeats as HCP9 then gives a long explanation (652 words) of various treatments and pros and cons during with little interaction from Stephen until]: Stephen: But at that stage, you being the experts would say 'this is the best course of treatment', it wouldn't be a thing where you would say to me 'right, here's your options, what do you fancy doing?'.

HCP9: We certainly can give you some guidance [...] actually has to be you that makes that decision ultimately.

Stephen: But that's only if it's pretty well 'even stevens'.

The additional dimension to rigidity is that, due to earlier dialogic experiences, Stephen has looked elsewhere for information. This is signalled in the dialogue but not acknowledged as excellence by the HCP, and rigidity is reinforced by offering more reading material.

Stephen: Well, [...] I've read is that [...] it's a process of elimination. Either it's there or it isn't and then if it is there, has it spread outside of the area into another area. HCP9: Yep.

Stephen: You know, instead of being serious it's very serious if it's spread.

[HCP9 then takes control of conversation and as before, produces a solution.]

HCP9: [...] So I'll give you some more stuff in terms of some reading material.

Stephen: Yes, yes.

In later dialogue, rigidity evolves into exclusion. The value of the dialogue between Stephen and HCP9 during a later review of his treatment is now wholly reliant on HCP9's excellence in interpreting the outcome. The medical result is excellent, but there is little evidence of any recognition of the excellence of both, no real development of knowledge, and Stephen brings little to the discussion.

HCP9: It was 90 grams so that was a decent size. Yes, that was a decent size of lump of prostate, 90 -odd grams. $[\ldots]$ what we call multi-focal, so there were a number of areas throughout the prostate gland.

Stephen: Oh.

HCP9: It was confined to the prostate gland and also surgical margins were clear.

Stephen: Right, good.

HCP9: And all the lymph nodes that I sent out were clear.

Stephen: Right.

$H C P$ : And PSA of less than 0.1 is as low as the test goes.

Stephen: Oh, right. 


\section{[Dialogue continues in this manner]}

HCP9: So the odds are very much that you are cured in the traditional way, i.e., you've got no cancer left [...] effectively the chance that you're going to be bothered by prostate cancer again is very, very, very, very, very low indeed.

Stephen: Right, excellent.

When solution promotion operates in dialogue, rather than the excellence of both parties developing over time, we see patient excellence become divorced from that of the professional, finally ending in withdrawal. In most cases, this effectively imposes the expert voice, states a specific treatment pathway, and closes down avenues for patient excellence to develop. The result is an externalized legitimacy of the solution and the personal implications of conditions and treatment are not integrated into the discourse. Thus, a negative influence on informed decision making, if offered. Nonetheless, we note it is not entirely without value in terms of medical outcomes. Patients also go elsewhere for information, which we can also construe as a type of value destruction.

\section{Co-destroying the value of "esteem"}

When denial of affirmation operates in early dialogue, esteem is important but is lacking being thwarted from emergence. In its stead we observe professional indifference. In the following extract, whilst HCP2 proceeds with eliciting a medication list from Rose, her attempts to integrate her negative emotional experience into the dialogue are denied and destroy the possibility of esteem.

HCP2: Do you have a list of those medications?

Rose: Yes - I am afraid I don't feel well today.

HCP2: OK. Is it OK if I get this bleep in the meanwhile?

Rose: Oh do.

HCP2: Sorry. [Made a phone call] Sorry about that.

Rose: I am afraid that's -

HCP2: OK, I will just take a note of these [medications].

In a subsequent consultation between HCP2 and Rose we see a similar dialogic engagement pattern emerging as denial of affirmation continues to operate. The outcome is one of suppression of esteem in terms of acknowledging emotions. When Rose continues to raise issue negative emotional experiences, denial of affirmation serves to suppress those experiences. We interpret this as destroying the potential esteem value that could have emerged between Rose and HCP2.

Rose: [...] I'm going up and down, I'm not managing it very well.
HCP2: You're not managing it very well.

Rose: No.

HCP2: OK. But with the changes in the medications that they've done, is it any better at all?

Rose: Well this I'm worried about because I understand it's - I mean what is that a sign of, that something's HCP2: Well it looks like there's some disruption of blood vessels but it's most likely drug related. I wouldn't worry too much about that because it will come back.

Rose: Will it?

HCP2: Yes. All your blood results were fine.

Rose: Good, OK.

HCP2: So it's probably related to your blood clotting, the main reason why you can have bruises, if there's anything that affects the clotting and that was all fine.

This destruction of value can persist over long periods of time. When HCP1 (M, 58), whom Rose has not seen for a year, tries to engage her in self-expression to recognize her experience, Rose instigates a denial of affirmation rejecting HCP1's efforts, and seemingly distances herself. The outcome of the operation of denial of affirmation over time being an alienation between the patient, the service, and the medical outcome (even when this is good). Rose is unable to find any emotional value even in the face of good news.

HCP1: Well done. Well done, well done, well done.

Rose: It's not me who's done anything.

HCP1: Yes, you have.

Rose: It's all the people -

HCP1: You've sat through it all. Come on then, let's have a look at you.

Rose: Right. [patient being examined]

HCP1: So you feel fine? No funny lumps or bumps?

Rose: I don't think so. I don't know what to expect.

HCP1: Well, I'm not expecting anything.

Rose: No, right.

In the case of denial of affirmation, we see the esteem value gradually destroyed over time. The opportunity for developing shared meaning is destroyed as there is unresolved anxiety, dissatisfaction, and frustration. An illustration of the longterm impact of unresolved anxiety on how a patient lives with a condition is clear in a sequence between the $\operatorname{HCP} 11(\mathrm{M}, 51)$, Jeremy (M, 70, Prostate Cancer) and his companion (C) about his problem with sleep:

HCP 11: It's unlikely to be anything to do with your prostate cancer at this point but I don't know what else is on your mind? 
$C$ : It's just the cancer. Since he found out that he had the cancer he's worried.

HCP11: But that's been a long time back.

Jeremy: It's five years in January.

Multiple values can also be co-destroyed, enabled by the identified co-destruction mechanisms. Co-destruction of value is equally contingent on prior interactions, being facilitated by unacknowledged, possibly competing, meanings. Over time we observe that the nature of value gradually deteriorates, where understanding of the condition remains at a medical level, and a progressive distancing between the parties develops (Table 3).

\section{Discussion}

The premise of this paper is that the nature of dialogue during face-to-face synchronous complex service interactions directly impacts on co-creation and co-destruction opportunities for consumer-relevant value. This premise is of particular relevance to the delivery of consumer-centered healthcare services. We utilize emerging insights in DE theory to extend our understanding of value co-creation and co-destruction and, hence, value-based service delivery. We clarify that over time dialogue during service interactions can be the foundation of the development of mutual (shared) value between professional service providers and consumers. We argue and demonstrate that the nature of engagement in dialogue facilitates value co-creation, but equally dialogue at this level can result in the co-destruction of value.

\section{Implications for theory}

To improve our understanding of the central role of interactions during service encounters, we identify at the granular level how professionals and consumers engage in dialogue. Our first contribution is to conceptualize and contextualize DE principles of ideal dialogue as three pairs of dialogic cocreation or co-destruction mechanisms for complex service interactions. We develop these mechanisms through combining the DE notion of tensions with the value co-creation notion of resource integration. We find evidence that our mechanisms work to surface tensions of power, legitimacy of perspective, and socio-emotional contexts between healthcare professionals and consumers. These tensions are resolved through effective integration of their knowledge resources, that is, the priorities, concerns, and experiences of both healthcare professional and consumer, thereby creating the enabling conditions to develop shared meaning between service providers and consumers. When tension resolution is unsuccessful value co-destruction ensues.
Our mechanisms help us to deepen our insights of the complexity of service interactions by empirically demonstrating the ways in which professionals and consumers engage in dialogue to aid or hinder communication. DE theorists question whether it is reasonable to expect dialogue to emerge in situations of strong power differentials and entrenched cultural role expectancies (Cissna and Anderson 2012), such as complex services like healthcare. Indeed, the mechanisms that we identify are not mutually exclusive and there are fuzzy boundaries between them as they often co-occur within the same service interaction. Nevertheless, in this study concerning HCP-patient interactions, in which power differentials might be assumed, we provide empirical evidence that dialogic engagement can occur. It is clear that not all interaction classifies as dialogic engagement. There is "small talk" and purposeful communication (e.g., taking medical histories). What is important is that enough "dialogic moments" (Cissna and Andersen 2012) are woven into the interactions. This has important implications for both $\mathrm{DE}$ and value cocreation in that despite situations not conducive to "ideal dialogue," still moments of DE and, thus, co-creation of value can be achieved. That is, the uneven power/knowledge situations that often characterize complex professional service encounters are not de facto a barrier to value co-creation.

Yet complex services pose a particular challenge to value co-creation as they involve multiple service providers and delivery takes place over time and linked interactions. Thus, we further our understanding of service interactions by examining the co-creation/destruction of value over the course of actual service delivery. Our second and substantive contribution is our conceptualization of consumer-relevant value in complex services, in which we specify the multidimensional nature and dynamic evolution of value across linked service interactions. In this we depart from the instrumental medical view of value, not focusing on discrete medical outcomes (e.g., recovery) and instead adopting the fluid view of value from DE (Kent and Taylor 2018), focusing on the possible shared value between service provider and consumer. We offer insights into three dynamic values pivotal to value cocreation and three dynamic values pivotal to value codestruction within complex services, which have their roots in Holbrook's (1999) values of efficiency, excellence, and esteem.

Related to the trajectories of care, we propose "ideal" dialogic pathways of value co-creation and value co-destruction (Fig. 1) that provide a holistic overview of the dialogic dynamics of how value co-creation/destruction develops across linked service interactions. Moving beyond static concepts of value, the co-creation pathway demonstrates the potential for values to evolve dynamically into shared values between professional and consumer. The outcome is a stronger basis upon which to pursue positive strategies, such as shared decision making. In the healthcare context, developing shared forms of 


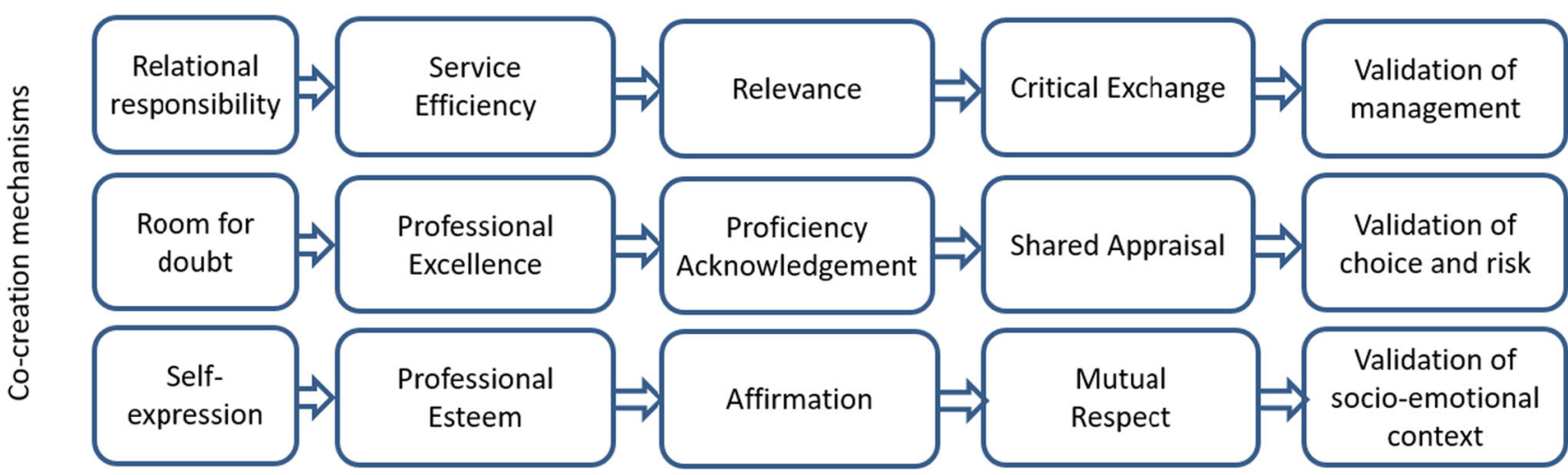

Evolving value

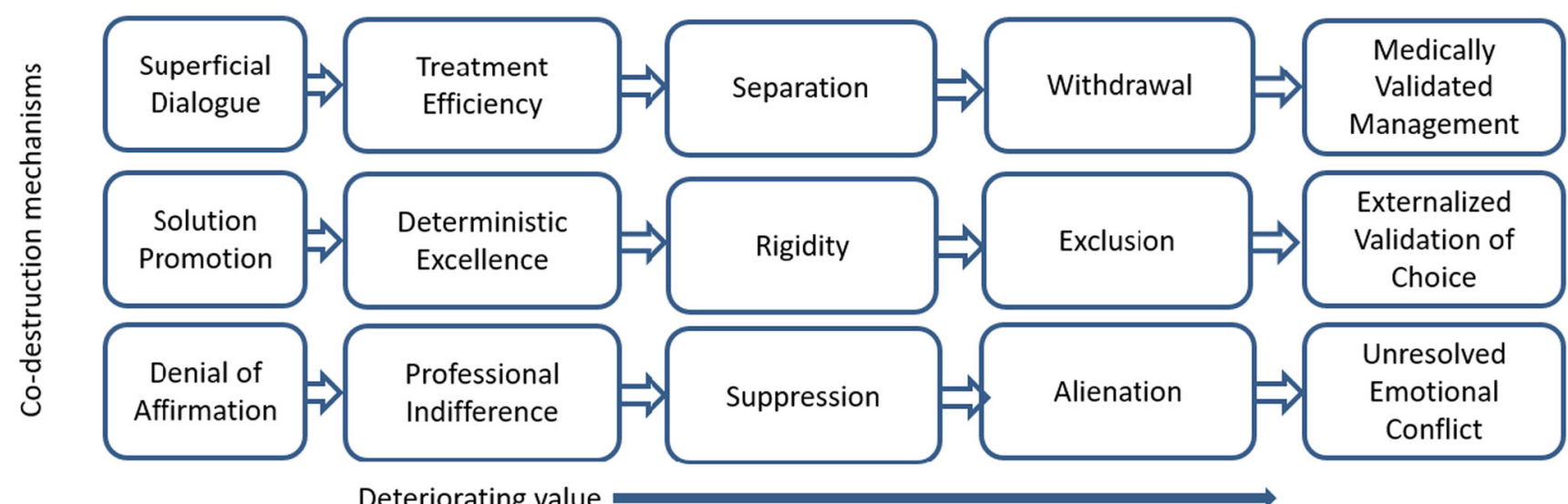

Fig. 1 Longitudinal creation or destruction of value. We identify two pathways: one for value co-creation and one for value co-destruction. Structured by these pathways, this figure shows how the dialogic cocreation and co-destruction mechanisms (on the left) link to specific values. The flow from these mechanisms demonstrates the process of how each value evolves or deteriorates over the course of interactions, and the outcomes are indicated (on the right). Refer to table 3 for the descriptions of evolving or deteriorating value efficiency, excellence, and esteem across service interactions can support mutual validation of the management, choices and risks, and socio-emotional vulnerabilities of health. These values emerging from dialogue not only support more aligned professional-consumer communications and increased quality of participation in dialogue, but also shared understanding can lead to more "buy-in" and ownership from the consumer and a strong relationship between professional and consumer based on mutual respect. The value co-destruction pathway can systematically lead to erosion of communication, participation, and positive relationships. Despite a medically positive outcome, this can leave consumers with unresolved tensions, frustration, and a division in the service-consumer relationship that may be difficult to recover.

By demonstrating how the cumulative consequences of dialogue unfold over service delivery, we add to theoretical attempts to understand the longitudinal aspects of cocreation (e.g., Razmdoost et al. 2019) and co-destruction (e.g., Mele 2011). This facilitates identification of possible cases where value may be co-created or co-destroyed, to inform the creation of adaptive complex service practices, e.g., sustainable consumer-professional partnerships. However, healthcare, as other complex services, is bounded by a number of conditions. For example, the discussion of the availability of other treatment choices is rare in our observations, and this may be due to the particular care agenda (or budget and hence availability) of the service provider, the severity/nature of the patient's condition, the time per patient, and the integration of care across conditions. Within (and despite) the contextual boundaries, we still see evidence of value co-creation. Further, we observe that few patient experiences are entirely negative (or positive); patients tend to have mixed experiences.

Positioning our work against ongoing research, we argue that the dialogic co-creation/destruction patterns that we identify influence the development of the capabilities needed for the roles and practices required for consumer-professional partnerships (Keeling et al. 2019; McColl- 
Kennedy et al. 2017; Palumbo 2017). These approaches focus on the wider aspects of consumer-professional relationships and the possibility of value through partnerships (e.g., enhanced quality of life). The dialogic processes that we identify in service interactions form the foundation for the enactment of these roles and practices by directly addressing and channeling the tensions between service providers and consumers. That is, this layer of shared values forms the basis for consumers and professionals to carry out preferred roles and practices within complex services. Importantly, patients may return to their priorities, concerns, or experiences with increasing persistence, until the tension is resolved or they make a direct challenge, corresponding to the amplification of motivation when important goals are not fulfilled (Fishbach et al. 2014). Thus, where priorities, concerns, and experiences are not resolved, there is increased likelihood of increasing disruption of the patient role in dialogue with negative consequences for value co-creation.

\section{Implications for complex services}

Our data suggest that in complex services an interaction strategy may be necessary to achieve $\mathrm{DE}$ and value co-creation conditions, despite the notion of strategy posing something of a dilemma for DE theory (White 2008). The dilemma is that theoretically dialogue is spontaneous and emergent, which appears incompatible with the evidence that often a strategy is implicit in interactions that achieve dialogic engagement (White 2008). Returning to calls for the specification of strategies that (1) address tensions in dialogue (Kent and Taylor 2018) and (2) enable value co-creation in real service contexts (Vargo and Lusch 2016), our mechanisms and value pathways identify how DE can support co-creation in practice in terms of improving interactions between service provider and consumer. This applies to the health services imperative of delivering consumer-centered care (Hardyman et al. 2015) and to other complex services, such as legal, financial, and education services, where

Table 4 Future research agenda: Key themes and questions

\begin{tabular}{|c|c|c|}
\hline Development areas & Research themes & Research questions \\
\hline \multirow{3}{*}{$\begin{array}{l}\text { DE Co-creation and } \\
\text { Co-Destruction } \\
\text { Mechanisms }\end{array}$} & Actor characteristics & $\begin{array}{l}\text { How do different actor goals influence the use of DE mechanisms? What are the } \\
\text { trait versus state influences on the operation of DE mechanisms? }\end{array}$ \\
\hline & Servicescape configurations & $\begin{array}{l}\text { What is the impact of the physical space within which the interactions take place on } \\
\text { the enactment of DE mechanisms? Can ambient stimuli be used to influence this? }\end{array}$ \\
\hline & $\begin{array}{l}\text { Roles in consumer-professional } \\
\text { partnerships }\end{array}$ & $\begin{array}{l}\text { What is the influence of the re-occurrence of conditions on individual DE } \\
\text { capabilities? Are there optimal configurations of DE mechanisms in supporting } \\
\text { successful partnerships? }\end{array}$ \\
\hline \multirow[t]{3}{*}{$\begin{array}{l}\text { Co-creation and } \\
\text { Co-destruction of Value }\end{array}$} & Influence of other actors & $\begin{array}{l}\text { Can value evolution or destruction be extended or shortened through the } \\
\text { unanticipated engagement of other actors (e.g., family members, carers, trainee } \\
\text { HCPs, translators)? How does collective engagement (e.g., professional or } \\
\text { support communities) influence dialogic engagement? }\end{array}$ \\
\hline & Non-linear trajectory of value & $\begin{array}{l}\text { Do different values evolve or deteriorate at different velocities? How are pathways } \\
\text { disrupted and/or cross-over between pathways occur? Does the length of time of } \\
\text { the extended service experience disrupt or cultivate the value } \\
\text { co-creation/destruction process? }\end{array}$ \\
\hline & Intervention strategies & $\begin{array}{l}\text { How can feedback mechanisms (e.g., asking questions and receiving feedback) be } \\
\text { enhanced? How can actors mitigate unintended consequences of value } \\
\text { creation/destruction? Does the flow of value co-creation/destruction differ } \\
\text { between acute and chronic conditions as a result of maturity of patient } \\
\text { knowledge and self-management? }\end{array}$ \\
\hline \multirow[t]{4}{*}{ Research Design } & $\begin{array}{l}\text { Extending to other complex service } \\
\text { contexts }\end{array}$ & $\begin{array}{l}\text { Do the same/different DE mechanisms underpin value co-creation/destruction in } \\
\text { other complex services (e.g., education, finance, legal)? How do large scale } \\
\text { changes or tipping points in the macro environment change things (e.g., } \\
\text { health/economic crises, financial regulations, privacy regulations)? }\end{array}$ \\
\hline & $\begin{array}{l}\text { Extending to other service delivery } \\
\text { modes and interactive platforms }\end{array}$ & $\begin{array}{l}\text { Does DE translate to complex service provision using distance delivery modes? } \\
\text { How can DE be applied in the use of interactive platforms, whether text-based } \\
\text { such as Twitter or integrated with visuals such as Instagram? }\end{array}$ \\
\hline & $\begin{array}{l}\text { Extending to accommodate multiway } \\
\text { interactions }\end{array}$ & $\begin{array}{l}\text { How to support the integration of multiple voices and allow multi-way interactions } \\
\text { that enhance dialogue and foster interactive dialogic loops? }\end{array}$ \\
\hline & Methodological extensions & $\begin{array}{l}\text { Using a mixed method approach, how can we develop a DE measurement scale? } \\
\text { And what is the appropriate longitudinal quantitative design to capture observed } \\
\text { and latent lagged changes? }\end{array}$ \\
\hline
\end{tabular}


similar tensions may also apply (Aarikka-Stenroos and Jaakkola 2012).

We found our dialogic value co-creation/destruction mechanisms to be common practice across consultations. Thus, identification of such mechanisms can be used to educate service providers and consumers in how to identify when such practices arise. For example, storytelling techniques could exemplify how patients and professionals jointly reach shared understanding that informs decisions about treatment through dialogue characterized by co-creation mechanisms. This approach could, additionally, help to combat issues relating to co-destruction mechanisms through raised awareness. Such techniques could in the case of professionals be applied in training, and in the case of consumers, be delivered through creating online video or other interactive marketing assets.

Pertinent to complex services, which increasingly rely on consumers to partly orchestrate their own service (e.g., home monitoring of health measures), in practice, our mechanisms can be used to determine interventions to promote consumercentered strategies, for example, shared decision-making. Value co-creation is partly dependent on achieving an appropriate division of activities, such that service providers can reduce their own efforts and increase those of the consumer (Payne et al. 2008). Our mechanisms demonstrate how consumers can engage in dialogue to more effectively integrate their resources. Service providers may be able to encourage consumer engagement through incorporating these mechanisms into dialogue from initial consultations, perhaps developing service scripts to help professionals incorporate this approach into their dialogue with consumers.

Whilst we focus on dyadic face to face dialogue, our mechanisms are equally applicable to other dialogue forms. For example, in the implementation of group consultations, the co-creation mechanisms can be used to guide actors through an effective value creating process. The efficacy of group discussion in online forums supports this value-creating potential (Keeling et al. 2015). Further, as artificial intelligence and digital technologies continue to influence service delivery, new forms of dialogue platforms (e.g., chat-bots) may be uniquely placed to offer dialogue that implements the cocreation mechanisms allowing for uniquely personalized experiences. Equally, they can be trained to identify the operation of co-destruction mechanisms.

In implementing such strategies, we must also take into account the critical bounding of dialogue. We have already raised the possible constraints that constrain dialogue (e.g., treatment availability or appropriateness, urgency of commencement of treatment, time available for consultations, healthcare systems) both in terms of its nature and also possible value to be extracted. Further, HCPs have a moral imperative to not let the patient take what they view as a harmful decision. Whilst patients may view their decisions and outcomes differently, this does limit how far dialogue can go. Other complex services providers face similar constraints (e.g., Aarikka-Stenroos \& Jaakkola 2012).

\section{Future research agenda}

To the best of our knowledge, we are amongst the first to explore $\mathrm{DE}$ as a theoretical domain in the study of value cocreation/destruction in complex services. Based on our findings and recognized limitations (relating to context) we offer a research agenda (Table 4) encompassing a set of both substantive theory- and design-related research avenues for further deepening our understanding of the role of DE in complex service settings.

As there is an increasing need for the co-creation of value in healthcare systems, it is imperative that we develop our thinking around DE, even to the extent that "if the structure does not permit dialogue the structure must be changed" (Freire, 1970, cited in McKenna, 2012, p. 95). We hope that this paper helps in guiding the direction of change and contributes to the dialogue around it.

Open Access This article is licensed under a Creative Commons Attribution 4.0 International License, which permits use, sharing, adaptation, distribution and reproduction in any medium or format, as long as you give appropriate credit to the original author(s) and the source, provide a link to the Creative Commons licence, and indicate if changes were made. The images or other third party material in this article are included in the article's Creative Commons licence, unless indicated otherwise in a credit line to the material. If material is not included in the article's Creative Commons licence and your intended use is not permitted by statutory regulation or exceeds the permitted use, you will need to obtain permission directly from the copyright holder. To view a copy of this licence, visit http://creativecommons.org/licenses/by/4.0/.

\section{References}

Aarikka-Stenroos, L., \& Jaakkola, E. (2012). Value co-creation in knowledge intensive business services: A dyadic perspective on the joint problem solving process. Industrial Marketing Management, 41(1), $15-14$.

Atkinson, M., \& Hammersley, P. (2007). Ethnography: Principles in Practice, Routledge, New York, 3rd edition.

Bakhtin, M.M. (1986) Speech Genres and Other Late Essays. Trans. By Vern W. McGee. Austin, Tx: University of Texas Press.

Banoun, A., Dufour, L., \& Andiappan, M. (2016). Evolution of a service ecosystem: Longitudinal evidence from multiple shared services centers based on the economies of worth framework. Journal of Business Research, 69(8), 2990-2998.

Bebbington, J., Brown, J., Frame, B., \& Thomson, I. (2007). Theorizing engagement: The potential of a critical dialogic approach. Accounting, Auditing \& Accountability Journal, 20(3), 356-381.

Beirão, G., Patrício, L., \& Fisk, R. (2017). Value cocreation in service ecosystems: Investigating health care at the micro, meso, and macro levels. Journal of Service Management, 28(2), 227-249.

Best, B., Moffett, S., \& McAdam, R. (2019). Stakeholder salience in public sector value co-creation. Public Management Review, 1-26. 
Chandler, J. D., \& Lusch, R. F. (2015). Service systems: A broadened framework and research agenda on value propositions, engagement, and service experience. Journal of Service Research, 18(1), 6-22.

Cissna, K. N., \& Anderson, R. (2012). Moments of meeting: Buber, Rogers, and the potential for public dialogue. NY, USA: SUNY Press.

Insights, D. (2018). The health plan of tomorrow: Disruption is picking up pace. Deloitte Development LLC.

Echeverri, P., \& Skalen, P. (2011). Co-creation and co-destruction: A practice-theory based study of interactive value formation. Marketing Theory, 11(3), 351-373.

Fishbach, A., Mingjung, K., \& Finkelstein, S. (2014). Motivation resulting from completed and missing actions. Advances in Experimental Social Psychology, 50, 257-307.

Freire, P. (1970). Pedagogy of the oppressed (MB Ramos, Trans.). New York: Continuum.

Freire, P. (2005). Pedagogy of the Oppressed (30th Anniversary ed.). New York, USA: Continuum (Original work published 1970).

Gergen, K.J., McNamee, S., \& Barrett, F.J. (2002). Realizing transformative dialogue. In Roberts, N. (Ed.), The Transformative Power of Dialogue (research in public policy analysis and management, volume 12) (pp. 77-105), Emerald Group publishing limited.

Grönroos, C., \& Voima, P. (2013). Critical service logic: Making sense of value creation and co-creation. Journal of the Academy of Marketing Science, 41(2), 133-150.

Hardyman, W., Daunt, K. L., \& Kitchener, M. J. (2015). Value cocreation through patient engagement in health care: A micro-level approach and research agenda. Public Management Review, 17(1), 90-107.

Health Foundation. (2012). Evidence: Helping people share decisionmaking, A review of evidence considering whether shared decision making is worthwhile. The Health Foundation: London.

Helkkula, A., \& Kelleher, C. (2010). Circularity of customer service experience and customer perceived value. Journal of Customer Behavior, 9(1), 37-53.

Helkkula, A., Kelleher, C., \& Pihlström, M. (2012). Characterizing value as an experience: Implications for service researchers and managers. Journal of Service Research, 15(1), 59-75.

Holbrook, M. B. (1999). Consumer value. A framework for analysis and research. Routledge: London.

Hollebeek, L. D., Srivastava, R. K., \& Chen, T. (2019). S-D logic-informed customer engagement: Integrative framework, revised fundamental propositions, and application to CRM. Journal of the Academy of Marketing Science, 47(1), 161-185.

Jaakkola, E., Helkkula, A., \& Aarikka-Stenroos, L. (2015). Service experience co-creation: Conceptualization, implications, and future research directions. Journal of Service Management, 26(2), 182-205.

Joseph-Williams, N., Lloyd, A., Edwards, A., Stobbart, L., Tomson, D., Macphail, S., Dodd, C., Brain, K., Elwyn, G., \& Thomson, R. (2017). Implementing shared decision making in the NHS: Lessons from the MAGIC programme. BMJ, 357(j1744).

Keeling, D. I., Laing, A., \& Newholm, T. (2015). Health communities as permissible space: Supporting negotiation to balance asymmetries. Psychology \& Marketing, 32(3), 303-318.

Keeling, D. I., Laing, A., \& de Ruyter, K. (2019). Evolving roles and structures of triadic engagement in healthcare. Journal of Service Management, 29(3), 352-377.

Kent, M.L., \& Taylor, M. (2018). Understanding the rhetoric of dialogue and the dialogue of rhetoric. In The Handbook of Organizational Rhetoric and Communication, Øyvind Ihlen Robert L. heath (eds.), 315-327, USA: John Wiley \& Sons.
Makkonen, H., \& Olkkonen, R. (2017). Interactive value formation in interorganizational relationships: Dynamic interchange between value co-creation, no-creation, and co-destruction. Marketing Theory, 17(4), 517-535.

Malshe, A., \& Friend, S. B. (2018). Initiating value co-creation: Dealing with non-receptive customers. Journal of the Academy of Marketing Science, 46(5), 895-920.

Martela, F., \& Steger, M. F. (2016). The three meanings of meaning in life: Distinguishing coherence, purpose, and significance. Journal of Positive Psychology, 11(5), 531-545.

McColl-Kennedy, J. R., Hogan, S. J., Witell, L., \& Snyder, H. (2017). Cocreative customer practices: Effects of health care customer value cocreation practices on well-being. Journal of Business Research, 70, 55-66.

McKenna, B. M. (2012). Medical education under siege: Critical pedagogy, primary care and the making of slave doctors. The International Journal of Critical Pedagogy, 4, 1.

Mele, C. (2011). Conflicts and value co-creation in project networks. Industrial Marketing Management, 40(8), 1377-1385.

Miles, M. B., \& Huberman, A. M. (1994). Qualitative data analysis. Thousand Oaks: Sage.

O'Leary, T. (1985). Observations on corporate financial reporting in the name of politics. Accounting. Organizations and Society, 10(1), 87102.

Palumbo, R. (2017). The bright side and the dark side of patient empowerment: Co-creation and co-destruction of value in the healthcare environment. Switzerland: Springer.

Payne, A. F., Storbacka, K., \& Frow, P. (2008). Managing the co-creation of value. Journal of the Academy of Marketing Science, 36(1), 8396.

Plé, L., \& Cáceres, R. (2010). Not always co-creation: Introducing interactional co-destruction of value in service-dominant logic. Journal of Services Marketing, 24(6), 430-437.

Razmdoost, K., Alinaghian, L., \& Smyth, H. J. (2019). Multiplex value cocreation in unique service exchange. Journal of Business Research, 96, 277-286.

Ritala, P., \& Tidström, A. (2014). Untangling the value-creation and value-appropriation elements of coopetition strategy: A longitudinal analysis on the firm and relational level. Scandinavian Journal of Management, 30(4), 498-515.

Sánchez-Fernández, R., Iniesta-Bonillo, M. Á., \& Holbrook, M. B. (2009). The conceptualisation and measurement of consumer value in services. International Journal of Market Research, 51(1), 1-17.

Saldana, J. (2013). The coding manual for qualitative researchers. London, UK: Sage.

Vargo, S. L., \& Lusch, R. F. (2016). Institutions and axioms: An extension and update of service-dominant logic. Journal of the Academy of Marketing Science, 44(1), 5-23.

Vargo, S. L., Akaka, M. A., \& Vaughan, C. M. (2017). Conceptualizing value: A service-ecosystem view. Journal of Creating Value, 3(2), $1-8$.

White, W. J. (2008). The Interlocutor's dilemma. Communication Theory, 18, 5-26.

Freire, P. (1970). Pedagogy of the oppressed (MB Ramos, Trans.). New York: Continuum.

Publisher's note Springer Nature remains neutral with regard to jurisdictional claims in published maps and institutional affiliations. 